\title{
Polychlorinated dioxins, furans, and biphenyls in blood of children and adults living in a dioxin-contaminated area in Tokyo
}

\author{
Chiharu Tohyama $\cdot$ Iwao Uchiyama $\cdot$ Shuji Hoshi $\cdot$ \\ Masaki Hijiya $\cdot$ Hideaki Miyata $\cdot$ Masaki Nagai $\cdot$ \\ Satoshi Nakai $\cdot$ Mariko Yauchi $\cdot$ Satsuki Ohkubo
}

Received: 8 December 2009/ Accepted: 4 May 2010/Published online: 15 June 2010

(c) The Japanese Society for Hygiene 2010

\begin{abstract}
The soil of a residential area in Tokyo was found to contain dioxins, namely polychlorinated dioxins, furans, and dioxin-like biphenyls, the levels of which exceeded the environmental guideline $[1,000 \mathrm{pg}$ toxic equivalent (TEQ)/g] by up to 6.8 times. To assess the exposure levels of people living in this area and to study the possible relationship of blood dioxin concentrations of children with breast milk and/or formula feeding, a health survey was carried out in 2006, involving a total of 138 people, including 66 children aged 3-15 years, and blood
\end{abstract}

This study is essentially based on a report entitled "Health survey on dioxins in Toshima area of Kita City" [19] by Kita City Office, Tokyo, and the authors, who played pivotal roles as members or secretariat of the expert committee for that survey, were given permission to use the original data to write this manuscript; the overall conclusions are essentially the same as those of that report.

Electronic supplementary material The online version of this article (doi:10.1007/s12199-010-0156-z) contains supplementary material, which is available to authorized users.

C. Tohyama ( $\square)$

Laboratory of Environmental Health Sciences,

Center for Disease Biology and Integrated Medicine,

Graduate School of Medicine, The University of Tokyo,

7-3-1 Hongo, Bunkyo-ku, Tokyo 113-0033, Japan

e-mail: mtohyama@mail.ecc.u-tokyo.ac.jp

I. Uchiyama

Graduate School of Engineering, Kyoto University,

Kyoto, Japan

S. Hoshi · M. Hijiya

IDEA Consultants, Inc., Tokyo, Japan

H. Miyata

Faculty of Pharmaceutical Sciences, Setsunan University,

Osaka, Japan dioxin concentrations and the characteristics and lifestyles of these people were analyzed. Mean \pm standard error of the mean (SEM) of blood dioxin concentrations (pg/ g-lipid) of group 1 (3-6 years old), group 2 (7-15 years old), and group 3 ( $\geq 16$ years old) were $13 \pm 1.9,6.6 \pm$ 0.65 , and $10 \pm 0.54$, respectively. The congener/isomer profile of dioxins in blood samples differed markedly from that of the contaminated soil samples. According to the feeding mode of children, blood dioxin concentrations (pg/glipid) were $17 \pm 2.9$ for breast milk only, $7.4 \pm 0.82$ for both breast milk and formula, and $4.7 \pm 1.1$ for formula only, with a significant difference from one another. We conclude that people living in the dioxin-contaminated area are less likely to be exposed to excessive amounts of dioxins, and that blood dioxin concentrations of children aged 3-15 years seem to be strongly affected by breast feeding duration.

Keywords Blood B Breast feeding C Children . Dioxin · Soil

M. Nagai

Department of Public Health, Faculty of Medicine,

Saitama Medical University, Saitama, Japan

S. Nakai

Graduate School of Environment and Information Sciences, Yokohama National University, Kanagawa, Japan

M. Yauchi $\cdot$ S. Ohkubo $(\bowtie)$

Public Health Center of Kita-City, 2-7-3 Higashi-jujo,

Kita-ku, Tokyo 114-0001, Japan

e-mail: S3-okubo@city.minato.tokyo.jp 


\section{Introduction}

Polychlorinated dibenzo- $p$-dioxins (PCDDs), polychlorinated dibenzofurans (PCDFs), and coplanar (or dioxin-like) polychlorinated biphenyls (CoPCBs), collectively referred to as dioxins hereinafter, are environmental contaminants that have attracted concerns regarding possible health effects worldwide because of a wide variety of toxicities associated with reproductive, neurological, and immunological abnormalities as well as carcinogenic effects [1]. During the reevaluation of risk assessment on PCDDs, PCDFs, and CoPCBs by the World Health Organization (WHO) in 1998, endpoints on reproductive, neurological, and immunological abnormalities owing to perinatal exposure to these chemicals were used as data to derive tolerable daily intake (TDI) level. The TDI level was amended from $10 \mathrm{pg}$ I-TEQ $/ \mathrm{kg}$ to be set at $1-4 \mathrm{pg}$ toxic equivalent (TEQ)/kg body weight and to include CoPCBs, which were not included in the I-TEQ values [2]. Such a stringent move regarding toxicity of dioxins and related compounds generated more serious concerns among people in Japan in the late 1990s and onwards. The main reasons for these concerns were associated with a few incidents, as follows. First, an extremely high level of dioxin soil contamination was discovered in the vicinity of a municipal incinerator in Osaka, Japan in November 1997, and workers who were engaged in the maintenance of the incinerator were found to have high blood dioxin concentrations, with mean concentration of $277.7 \mathrm{pg}$ TEQ/g-fat in 15 workers [3]. Second, in February 1999, a very popular TV news program reported that a high level of dioxins was detected in certain types of vegetables that were harvested in an area adjacent to an industrial waste incinerator complex in the outskirts of Tokyo. Although this news was later found to be inaccurate and misleading, it had already caused serious economic damage to farmers whose agricultural products remained unsold. Given these social backgrounds, the Japanese Government enacted the Law Concerning Special Measures against Dioxins, the so-called Dioxin Law, in July 1999. Following the reevaluation of the TDI level of dioxins to $4 \mathrm{pg} \mathrm{TEQ} / \mathrm{kg}$ and its inclusion in the Dioxin Law, environmental standards of dioxins were set for atmosphere, water, sediment, and soil. The environmental standard for soil is $1,000 \mathrm{pg} \mathrm{TEQ} / \mathrm{g}$, and its precautionary guideline level is set at $250 \mathrm{pg}$ TEQ/g. Third, the amount of dioxins ingested by babies from breast milk is estimated to be approximately $647 \mathrm{pg} \mathrm{TEQ} / \mathrm{day}$, assuming that the dioxin concentrations in milk, milk volume ingested per day, fat concentration in milk, and average body weight at the age of 6 months of Japanese infants are $22.7 \mathrm{pg}$ TEQ/g-lipid [4], $3.8 \%$ [5], $750 \mathrm{~mL}$, and $7.0 \mathrm{~kg}$, respectively. Thus, the amount of dioxins ingested via breast milk is estimated to significantly exceed the current TDI of $4 \mathrm{pg} T E Q / \mathrm{kg} / \mathrm{day}$, although dioxin and polychlorinated biphenyl (PCB) concentrations in breast milk have decreased to approximately one-third compared with those in the early 1970s [6, 7]. This situation is similar to that in the Netherlands, where the daily TEQ intake per kilogram body weight is 50 times higher in breast-fed infants and three times higher in toddlers than in adults [8]. Although the beneficial effects of breast feeding on the development of babies was disseminated together with the reevaluation of the risk of dioxins and related compounds by the WHO in 1998 [2] and later by governments including that of Japan, the excessive exposure to dioxins even during a limited nursing period aroused the concern of nursing mothers.

In 2005, when a piece of land in Kita City, Tokyo, which had been used as a school ground was examined for possible contamination with chemicals in accordance with the Ordinance of Environmental Preservation promulgated by the Tokyo Metropolitan Government, one of the soil samples was found to contain dioxins at 14,000 pg TEQ/g. Further investigations around this area revealed that the land adjacent to a large apartment complex (approximately 5,000 families and 10,000 habitants) was contaminated with dioxins. This soil contamination survey was carried out in accordance with the Environment Conservation Ordinance for soil contaminated with dioxins, the level of which was found to exceed the environmental standard $(1,000 \mathrm{pg}$ TEQ/g) by up to 6.8 times. This is the first case in Japan where soil contamination by dioxins was found in a residential area and playground for children, who may be exposed to the compounds by handling the soil directly. This incident generated much anxiety in the community. Thus, the Kita City Office organized an expert committee to form a strategy for and carry out a health survey, focusing on blood dioxin concentrations and the health examination of inhabitants in this contaminated area. Using these data compiled by the Kita City Office, we investigated whether blood dioxin concentrations were associated with contaminated soil in terms of congener/isomer patterns. In addition, we studied the possible relationship of feeding mode, i.e., breast milk and/or formula milk, with blood dioxin concentrations in children.

\section{Materials and methods}

\section{Target area}

An apartment complex (approximately 5,000 families and 10,000 residents) that includes an elementary school, a junior high school, a nursery, and a shopping mall was constructed in the 1960s on land where a chemical factory had been in operation until 40 years before. In 2005, a soil contamination survey was carried out as a joint project of 
the Kita City Office and Urban Renaissance Agency in 2005, in accordance with the Environment Conservation Ordinance of the Tokyo Metropolitan Government prior to this health survey. It was found that 7 soil samples out of 57 different locations in this apartment complex area contained dioxins, the level of which exceeded the environmental standard for soil $(1,000 \mathrm{pg} \mathrm{TEQ} / \mathrm{g})$ by up to 6.8 times. According to the analysis, the nursery yard and playgrounds were considered to be contaminated with dioxins. Thus, the Kita City Office selected this as a target area for health survey.

\section{Target population}

The Kita City Office disseminated information on the objectives of the health survey to the people living around the contaminated area through the city newsletter and at public meetings, and called for applications to participate in the health survey. Subjects were selected from 248 applicants on the basis of the following criteria: (1) to assess exposure levels to dioxins, children, who are considered to have frequent and direct contact with soil, had priority over adults; (2) among children, higher graders of the elementary school in the area had priority over the lower ones, who may still be considered to be under the influence of breast milk dioxins; (3) women of reproductive age had priority over other adults because of their concerns regarding dioxin contamination during their prospective pregnancy; (4) infants under 6 years old who were fed with breast milk only or also in combination with formula were recruited with their mothers as a pair for this survey; and (5) people who had lived longer in the apartment complex had priority over those who had lived there for less time. On the basis of these criteria, adults and children who were suspected of being frequently exposed to contaminated soil were selected as subjects of this health survey. The total number of subjects was 138 (52 males and 86 females). Their average (range) age was 13.9 (3-36) years for men and 22.9 (362) years for women. Out of 91 infants who were considered to be exposed to dioxins via soil of the nursery playground 23 of them participated in this study.

In the health survey performed in 2006, the subjects were requested to complete questionnaires concerning their personal history and lifestyles in advance, and were individually interviewed by public health nurses concerning their lifestyles, such as residential period, period of attendance at the day-care nursery, estimated times of soil contact, food habit, and pregnancy episode. In particular, to evaluate the frequency of soil contact of children as a source of dioxin exposure, those who were 3-15 years old were classified into four groups according to their habit of playing with soil as well as the chance of taking the soil into the mouth using the criteria described in "Results".
To study the possible relationship of breast feeding as the mode of nursing with blood dioxin concentrations, information regarding the length of nursing period by breast milk only, breast milk and formula in combination, or formula only was obtained from female subjects who had such an experience.

The general health conditions of the subjects were examined by medical doctors, and blood $(7 \mathrm{~mL}$ from children 6 years or younger, $14 \mathrm{~mL}$ from other subjects) was drawn from a vein of the forearm for dioxin and clinical chemistry analyses.

\section{Dioxin analysis}

Dioxin and related compounds, composed of a total of 29 congeners belonging to PCDDs, PCDFs, and CoPCBs in the blood and soil, were determined by IDEA Consultants, Inc., Shizuoka, Japan, by isotope dilution high-resolution gas chromatography/mass spectrometry (GC/MS) after liquid/liquid extraction and gel clean-up. The analytical method for these chemicals is prescribed by the Ministry of the Environment [9], and the detailed procedure was reported previously [10]. Blood lipid (\%) was measured gravimetrically using sulfuric ammonium-ethanol/hexane technique, and lipid content was used to normalize blood dioxin concentrations. The data of soil dioxins were kindly provided to us by the Kita City Office to study the possible relationship with blood dioxins. Toxic equivalence factors (TEFs) of the 29 congeners as revised by WHO in 2005 were used to calculate TEQs in this study [11].

\section{Statistical analysis}

In this health survey, differences in the concentrations of dioxins and related compounds between two groups were tested by Mann-Whitney (two-sided) test, and those among three to four groups were tested by Kruskal-Wallis (twosided) test, followed by Steel-Dwass ad hoc test. A $p$ value $<0.05$ or 0.01 was considered statistically significant. We used Statistica software (StatSoft Japan, Tokyo, Japan) for analysis.

\section{Informed consent}

This survey was performed by the Kita City Office to obtain information on the health status and exposure situation of the local residents in this dioxin-contaminated area following the principles of the Declaration of Helsinki. Prior to the survey, the people, who freely decided to participate in this survey, signed and submitted to the Kita City Office a written consent. In the case of children, their parents submitted a written consent on their behalf. According to the conditions of the informed consent, Kita 
City Office disseminated the health survey report [12]. Furthermore, transfer and use of this health survey data by the authors to write this paper, with the individual identification code removed, were approved by the Medical Ethics Committee of the Graduate School of Medicine of the University of Tokyo.

\section{Results}

Dioxin concentrations in blood

Concentrations of PCDDs + PCDFs, CoPCBs, and the sum of PCDDs + PCDFs + CoPCBs in blood from subjects who lived around the dioxin-contaminated area are summarized in Table 1. The concentrations (mean \pm SEM) of the sum of PCDDs + PCDFs + CoPCBs in the blood of male and female subjects who were 3-6 years old, $7-15$ years old, and 16 years or older were $13 \pm 1.9$, $6.6 \pm 0.65$, and $10 \pm 0.54 \mathrm{pg} \mathrm{TEQ} / \mathrm{g}$-lipid, respectively. There was no statistical difference in the concentrations of these chemicals among the age groups. The relatively high concentrations of these chemicals found in the present target population were 44 and $46 \mathrm{pg}$ TEQ/g-lipid in 3-yearold male and female subjects, respectively (Table 1). Because, to the best of our knowledge, no data on blood dioxin concentrations of children 12 years or younger is available, no direct comparison with the present results was possible. However, there are several surveys on blood dioxin levels of people older than 13 years. Thus, the blood dioxin concentrations of people in the present study were compared with those of people in Japan who were not accidentally exposed to excessive amounts of dioxins (Table 2). A series of surveys was performed by the

Table 1 Concentrations of dioxins and related compounds in blood of people living around the dioxin-contaminated area in Tokyo

\begin{tabular}{|c|c|c|c|c|c|}
\hline \multirow[t]{2}{*}{ Sex } & \multirow[t]{2}{*}{ Age } & \multirow{2}{*}{$\begin{array}{l}\text { No. of } \\
\text { subjects }\end{array}$} & \multicolumn{3}{|l|}{ Dioxin (pg TEQ/g-lipid) ${ }^{\mathrm{a}}$} \\
\hline & & & PCDDs + PCDFs & CoPCBs & $\mathrm{PCDDs}+\mathrm{PCDFs}+\mathrm{CoPCBs}$ \\
\hline \multirow[t]{3}{*}{ Male } & $3-6$ & 16 & $10 \pm 2.0(7.0,0.92-33)$ & $4.0 \pm 0.69(3.1,0.068-10)$ & $14 \pm 2.7(9.6,0.98-44)$ \\
\hline & $7-15$ & 20 & $5.4 \pm 0.61(5.0,0.98-14)$ & $1.6 \pm 0.34(1.1,0.061-4.8)$ & $7.0 \pm 0.87(6.3,1.0-18)$ \\
\hline & $\geq 16$ & 16 & $6.4 \pm 0.47(6.5,3.2-9.5)$ & $2.4 \pm 0.27(2.1,0.73-4.9)$ & $8.8 \pm 0.61(9.3,4.6-12)$ \\
\hline \multirow[t]{3}{*}{ Female } & $3-6$ & 17 & $8.3 \pm 1.9(5.1,0.85-31)$ & $3.1 \pm 0.950(1.5,0.053-16)$ & $11 \pm 2.8(5.9,0.94-46)$ \\
\hline & $7-15$ & 13 & $4.3 \pm 0.67(3.4,1.3-9.2)$ & $1.7 \pm 0.48(1.1,0.059-6.2)$ & $6.0 \pm 1.0(4.6,1.4-15)$ \\
\hline & $\geq 16$ & 56 & $7.7 \pm 0.55(7.0,0.70-24)$ & $3.3 \pm 0.21(2.9,0.065-7.1)$ & $11 \pm 0.66(10,2.8-29)$ \\
\hline \multirow[t]{3}{*}{ Total } & $3-6$ & 33 & $9.2 \pm 1.4(6.6,0.85-33)$ & $3.6 \pm 0.59(2.5,0.053-16)$ & $13 \pm 1.9(9.4,0.94-46)$ \\
\hline & $7-15$ & 33 & $5.0 \pm 0.45(4.4,0.98-14)$ & $1.7 \pm 0.27(1.1,0.059-6.2)$ & $6.6 \pm 0.65(5.7,1.0-18)$ \\
\hline & $\geq 16$ & 72 & $7.4 \pm 0.44(6.7,0.70-24)$ & $3.1 \pm 0.18(2.8,0.065-7.1)$ & $10 \pm 0.54(10,2.8-29)$ \\
\hline
\end{tabular}

No statistical difference between groups was present by Kruskal-Wallis test

${ }^{a}$ Values expressed as mean \pm SEM (median, range)

Table 2 Comparison of blood dioxin concentrations in the current study with those obtained in other studies in Japan

\begin{tabular}{|c|c|c|c|c|c|c|}
\hline \multirow{2}{*}{$\frac{\text { Organizer }}{\text { Year }}$} & \multicolumn{5}{|c|}{ Ministry of the Environment $[9,12]$} & \multirow{2}{*}{$\begin{array}{l}\text { Hachioji City [13] } \\
2004\end{array}$} \\
\hline & 2002 & 2003 & 2004 & 2005 & 2006 & \\
\hline Number of districts ${ }^{\mathrm{a}}$ & 14 & 15 & 15 & 15 & 15 & $\begin{array}{l}\text { Junior high } \\
\text { school }\end{array}$ \\
\hline Number of subjects [13] & 259 & 272 & 264 & 288 & 291 & 12 \\
\hline Age (years) & $\begin{array}{l}44.4 \pm 0.92 \\
\quad(45.0,16-72)\end{array}$ & $\begin{array}{l}41.7 \pm 0.78 \\
\quad(43.0,15-69)\end{array}$ & $\begin{array}{l}45.2 \pm 0.84 \\
\quad(46.5,15-70)\end{array}$ & $\begin{array}{l}44.3 \pm 0.86 \\
\quad(46.0,15-70)\end{array}$ & $\begin{array}{l}43.0 \pm 0.85 \\
\quad(42.0,15-72)\end{array}$ & $\begin{array}{l}13.3 \pm 0.14 \\
\quad(13.0,13-14)\end{array}$ \\
\hline $\begin{array}{l}\text { PCDDs + PCDFs } \\
\text { (pg TEQ/g-lipid) }\end{array}$ & $\begin{array}{l}13 \pm 0.49 \\
(12,0.44-52)\end{array}$ & $\begin{array}{l}13 \pm 0.42 \\
\quad(11,2.2-46)\end{array}$ & $\begin{array}{l}13 \pm 0.50 \\
\quad(11,0.57-53)\end{array}$ & $\begin{array}{l}12 \pm 0.46 \\
\quad(10,0.40-54)\end{array}$ & $\begin{array}{l}11 \pm 0.43 \\
(8.9,0.79-61)\end{array}$ & $\begin{array}{l}5.8 \pm 0.66 \\
\quad(4.8,3.4-9.5)\end{array}$ \\
\hline $\begin{array}{l}\text { CoPCBs } \\
\text { (pg TEQ/g-lipid) }\end{array}$ & $\begin{array}{l}8.4 \pm 0.46 \\
\quad(6.5,0.061-59)\end{array}$ & $\begin{array}{l}7.0 \pm 0.33 \\
(5.3,0.042-51)\end{array}$ & $\begin{array}{l}6.9 \pm 0.37 \\
\quad(5.2,0.064-48)\end{array}$ & $\begin{array}{l}9.3 \pm 0.47 \\
\quad(6.3,0.087-45)\end{array}$ & $\begin{array}{l}6.8 \pm 0.35 \\
\quad(4.9,0.013-34)\end{array}$ & $\begin{array}{l}1.2 \pm 0.25 \\
(1.3,0.10-2.3)\end{array}$ \\
\hline $\begin{array}{l}\text { PCDDs + PCDFs } \\
+ \text { + CoPCBs (pg TEQ/g-lipid) }\end{array}$ & $\begin{array}{l}22 \pm 0.90 \\
\quad(19,0.96-95)\end{array}$ & $\begin{array}{l}19 \pm 0.71 \\
\quad(17,2.7-97)\end{array}$ & $\begin{array}{l}19 \pm 0.81 \\
\quad(16,0.64-85)\end{array}$ & $\begin{array}{l}22 \pm 0.86 \\
\quad(17,1.5-75)\end{array}$ & $\begin{array}{l}17 \pm 0.70 \\
\quad(14,0.82-67)\end{array}$ & $\begin{array}{l}7.0 \pm 0.79 \\
\quad(6.7,3.5-11)\end{array}$ \\
\hline
\end{tabular}

Values expressed as mean \pm SEM (median, range)

a In the surveys organized by the Ministry of the Environment, districts were selected on a town or village level from five regions from all over Japan, and districts were different every year 


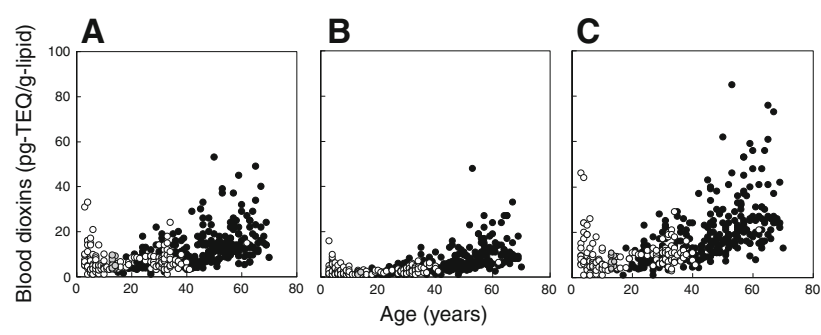

Fig. 1 Relationship of blood dioxin concentrations (pg TEQ/g-lipid) with age in the present study $(n=138$, open circle $)$, the 2004 Ministry of the Environment survey ( $n=264$, closed circle), and the 2004 Hachioji City study ( $n=12$, gray circle)

Ministry of the Environment to determine the general trend of concentrations of dioxins and related compounds by area and year. Thus, people aged 15 years and older participated in the survey in 14 or 15 areas all over Japan, and were found to have average values of $17-22 \mathrm{pg}$ TEQ/g-lipid with a range of $0.64-97 \mathrm{pg} \mathrm{TEQ/g-lipid} \mathrm{during} \mathrm{the} \mathrm{period}$ from 2002 to 2006 [9, 13]. Another survey was performed by Hachioji City in a suburb of Tokyo in 2004 [14], to examine blood dioxin concentrations of junior high school students who were accidentally exposed to vapor or aerosol of PCBs and dioxins because of the explosion of a fluorescent light stabilizer produced in the early 1970s that contained PCBs; the average \pm SEM blood dioxin concentration was $7.0 \pm 0.79 \mathrm{pg} \mathrm{TEQ} / \mathrm{g}$-lipid. Comparison with these study results shows that the blood dioxin concentrations of people 13 years and older in the present study were similar (Fig. 1).

\section{Comparison of congener patterns in blood and soil}

The soil samples from the contaminated area were found to have the unique feature of PCDFs as an overwhelmingly predominant component compared with blood samples (Fig. 2). The congener analyses of dioxins and related compounds showed that soil had larger amounts of tetra (Te)CDF, penta (Pe)CDFs, and hexa (Hx)CDFs on a mass basis and also on a TEQ basis than blood, and that blood had large amounts of octa (O)CDD on a mass basis, and penta $(\mathrm{Pe}) \mathrm{CDD}$, hexa (Hx)CDDs, PeCDFs, and HxCDFs on a TEQ basis than soil. The contributions of these congeners to total TEQ in the soil samples were $98.4 \%$ for PCDFs, $1.35 \%$ for PCDDs, and $0.29 \%$ for CoPCBs, whereas those in the blood samples were $42.5 \%$ for PCDDs, $26.5 \%$ for PCDFs, and $31.1 \%$ for CoPCBs. More precisely, the isomer analysis showed that the soil had larger amounts of 2,3,7,8-TeCDF, 1,2,3,7,8-PeCDF, $2,3,4,7,8-\mathrm{PeCDF}$, and $1,2,3,4,7,8-\mathrm{HxCDF}$ on a mass basis and 2,3,7,8-TeCDF, 2,3,4,7,8-PeCDF, and 1,2,3,4,7,8HxCDF on a TEQ basis than the other isomers. In contrast, blood samples contained larger amounts of OCDD on a mass basis, and 1,2,3,7,8-PeCDD and 1,2,3,6,7,8-HxCDD as well as $2,3,4,7,8$-PeCDF on a TEQ basis than the other isomers. Congener and isomer analyses of CoPCBs showed that the soil and blood samples had similar congeners and isomers, i.e., $2^{\prime}, 3,4,4^{\prime}, 5-\mathrm{PeCB}$ (PCB118) on a mass

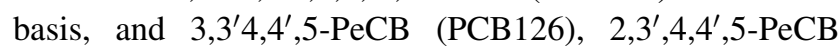

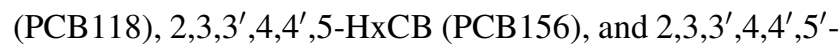
HxCB (PCB157) on a TEQ basis.

Period of residence, period of attendance at the day-care nursery, and frequency of soil contact

We divided all the subjects into two groups according to length of residence using the median of 10.3 years to compare blood dioxin concentrations. Mean \pm SEM of residential period for the two groups was $5.3 \pm 0.35$ and $25.2 \pm 0.90$ years. No significant differences were found in the amounts of PCDDs + PCDFs, CoPCBs, and PCDDs + PCDFs + CoPCBs between the two groups. Next, to analyze the possible association with attendance at a nursery whose ground was contaminated with dioxins, we divided the children aged 3-6 years into two groups depending on attendance at the nursery (Table 3). However, there was no significant relationship between these parameters.

Because greater hand-to-mouth contact rates may lead to more intake of dioxins present in the environment, we studied the possible relationship of blood dioxin concentrations with frequency of soil contact, and classified children aged 3-15 years into four groups according to the following criteria (Table 4): groups A and B, children who played with soil in playgrounds in this apartment complex until the time of this health survey; groups $\mathrm{C}$ and $\mathrm{D}$, children who did not play with soil at the time of this health survey but had experienced playing with soil in playgrounds in this apartment complex before; groups A and C, children who had frequent chances to put pieces of soil into the mouth; groups B and D, children who rarely had a chance to put pieces of soil into the mouth. When children belonging to groups $\mathrm{A}$ and $\mathrm{B}$ were compared with each other for PCDDs + PCDFs, CoPCBs or PCDDs + PCDFs + CoPCBs, no statistical difference was observed. The same was true for children belonging to groups $\mathrm{C}$ and $\mathrm{D}$.

Relationship of breast milk or formula with blood dioxin concentrations

To determine whether breast milk or formula affected the concentration of dioxins in children during their growth, we divided the 66 children aged 3-15 years into three groups of children who were fed with: breast milk only (group $\mathrm{Br}$ ), breast milk and formula in combination (group $\mathrm{BrFo}$ ), and 
Fig. 2 Comparison of dioxin profiles (congener and isomer compositions) in blood samples of subjects $(n=248)$ and those in a representative most highly contaminated soil sample (0-5 cm from the surface) of a nursery ground in a dioxincontaminated area of Kita City, Tokyo: congener compositions (a, d), isomers of PCDDs and PCDFs $(\mathbf{b}, \mathbf{e})$, and isomers of coplanar PCBs (c, f). Amounts of congeners and isomers are shown on a mass basis $(\mathbf{a}-\mathbf{c})$ and on a TEQ basis $(\mathbf{d}-\mathbf{f})$
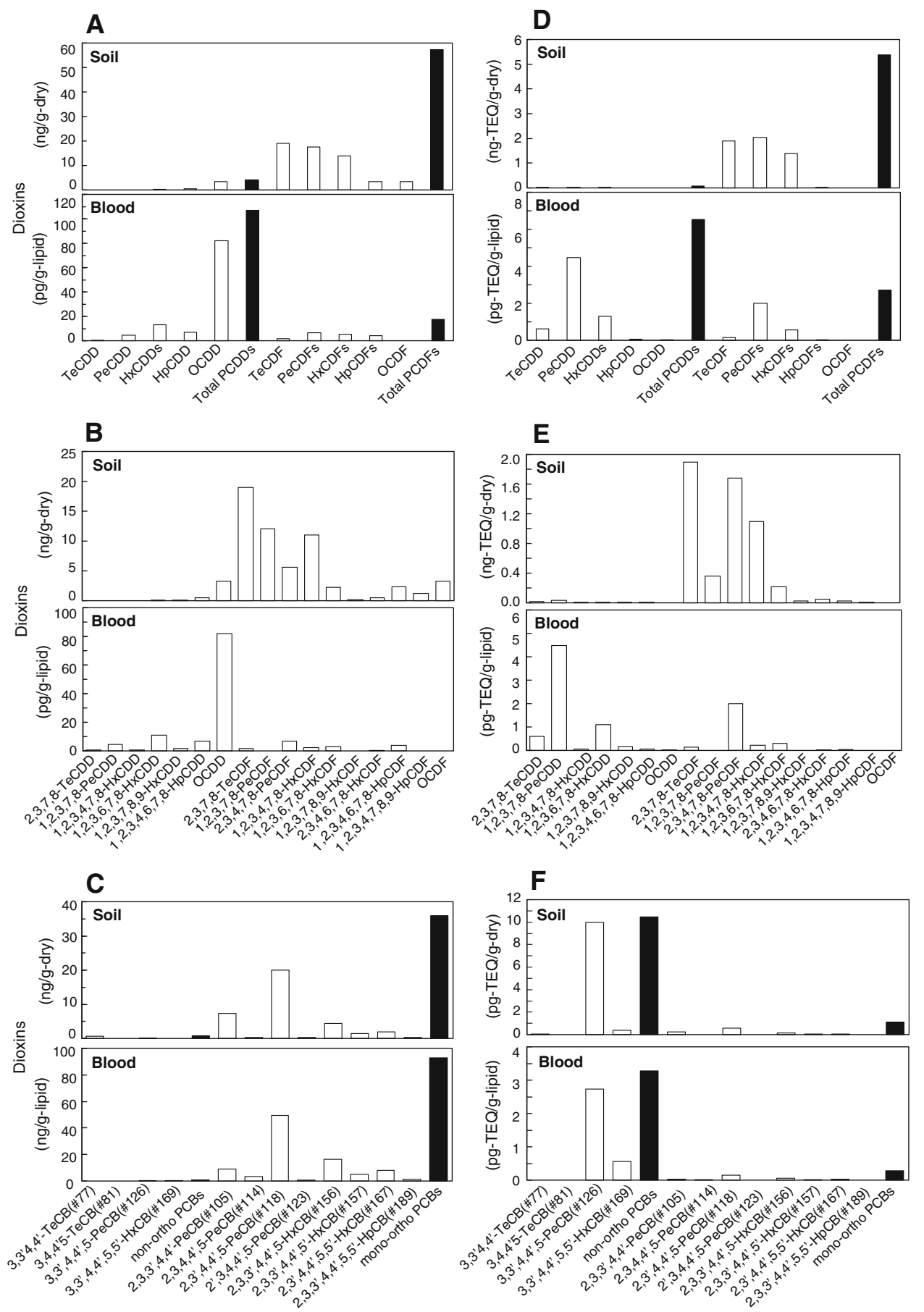

formula only (group Fo). It was not possible to obtain information about the details of the percentage of breast milk and that of formula of group BrFo. The concentrations of the sum of PCDDs + PCDFs + CoPCBs in the blood (mean $\pm \mathrm{SEM}$ ) for groups $\mathrm{Br}, \mathrm{BrFo}$, and $\mathrm{Fo}$ were $17 \pm 2.9, \quad 7.4 \pm 0.82$, and $4.7 \pm 1.1 \mathrm{pg} \mathrm{TEQ} / \mathrm{g}$-lipid, respectively (Table 5). As a whole, children belonging to group $\mathrm{Br}$ had significantly higher blood dioxin concentrations than those belonging to groups BrFo and Fo $(p<0.01$ and 0.05 , respectively). Similar statistical differences between these groups were detected for PCDDs + PCDFs and for CoPCBs.

When blood dioxin concentrations were plotted as a function of duration of breast feeding, there were statistically significant correlations between these two parameters for PCDDs + PCDFs $\left(R^{2}=0.78, p<0.01\right)$, CoPCBs $\left(R^{2}=0.56, p<0.01\right)$, and PCDDs + PCDFs + CoPCBs $\left(R^{2}=0.75, p<0.01\right)$, although this data is cross-sectional 
Table 3 Relationship of blood dioxin concentrations with attendance at the nursery with a dioxin-contaminated playground

${ }^{a}$ Values expressed as mean \pm SEM (median, range)

$n s$ not significant at $p=0.05$ by using Mann-Whitney test

\begin{tabular}{llll}
\hline $\begin{array}{l}\text { Dioxin concentrations in blood } \\
\text { (pg TEQ/g-fat) }\end{array}$ & \multicolumn{2}{l}{ Attendance at the nursery ${ }^{\mathrm{a}}$} & \multirow{2}{*}{$p$ value } \\
\cline { 2 - 3 } & Yes & No & \\
\hline PCDDs + PCDFs & & & \\
$\quad$ All subjects & $6.8 \pm 0.91(4.9,0.85-33)$ & $7.5 \pm 0.45(6.6,0.70-24)$ & $\mathrm{ns}$ \\
$\quad$ 3-6 years & $9.2 \pm 1.8(6.6,0.85-33)$ & $9.1 \pm 2.1(7.6,0.88-21)$ & $\mathrm{ns}$ \\
CoPCBs & $2.5 \pm 0.39(2.1,0.061-16)$ & $3.1 \pm 0.20(2.8,0.053-8.7)$ & $\mathrm{ns}$ \\
$\quad \begin{array}{lll}\text { All subjects } \\
\text { 3-6 years }\end{array}$ & $3.4 \pm 0.74(2.2,0.068-16)$ & $3.9 \pm 1.0(3.8,0.053-8.7)$ & $\mathrm{ns}$ \\
PCDDs + PCDFs + CoPCBs & & & \\
All subjects & $9.3 \pm 1.3(6.5,0.98-46)$ & $10 \pm 0.58(9.8,0.94-29)$ & $\mathrm{ns}$ \\
3-6 years & $13 \pm 2.5(9.4,0.98-46)$ & $13 \pm 3.0(12,0.94-26)$ & $\mathrm{ns}$ \\
\hline
\end{tabular}

Table 4 Relationship of blood dioxin concentrations with playing with soil in children aged 3-15 years

\begin{tabular}{|c|c|c|c|c|c|}
\hline $\begin{array}{l}\text { Blood dioxin } \\
\text { concentration } \\
\text { (pg TEQ/g-fat) }\end{array}$ & Group $A^{a}$ & Group B & Group C & Group D & $p$ value \\
\hline $\begin{array}{l}\text { Number } \\
\text { of subjects }\end{array}$ & 8 & 13 & 19 & 26 & \\
\hline Age (years) & $5.5 \pm 0.50(5.0,4-8)$ & $4.7 \pm 0.40(4.0,3-8)$ & $7.3 \pm 0.70(7.0,3-15)$ & $8.2 \pm 0.60(8.0,3-15)$ & $* *$ \\
\hline PCDDs + PCDFs & $6.6 \pm 1.6(5.0,0.92-15)$ & $10 \pm 2.5(7.0,0.88-33)$ & $4.6 \pm 0.51(4.3,0.85-10)$ & $7.5 \pm 1.3(5.1,0.98-31)$ & ns \\
\hline $\mathrm{CoPCBs}$ & $2.1 \pm 0.72(1.5,0.068-6.2)$ & $3.8 \pm 0.92(2.5,0.053-10)$ & $1.6 \pm 0.24(1.5,0.059-2.8)$ & $3.0 \pm 0.66(2.5,0.061-16)$ & ns \\
\hline $\begin{array}{l}\text { PCDDs + PCDFs } \\
+ \text { CoPCBs }\end{array}$ & $8.6 \pm 2.2(6.8,0.98-19)$ & $14 \pm 3.4(9.6,0.94-44)$ & $6.2 \pm 0.63(5.5,1.9-13)$ & $10 \pm 1.9(6.4,1.0-46)$ & ns \\
\hline
\end{tabular}

** Significantly different among groups at $p=0.01 ; n s$ not significant at $p=0.05$ by using Kruskal-Wallis test

${ }^{\text {a }}$ Values expressed as mean \pm SEM (median, range)

${ }^{b}$ Groups A and B, children who played with soil in the playgrounds in this apartment complex until the time of this health survey; groups C and $\mathrm{D}$, children who did not play with soil any longer in playgrounds in this apartment complex but who had experienced playing with soil before; groups $\mathrm{A}$ and $\mathrm{C}$, children who had frequent chances to put pieces of soil into the mouth; groups $\mathrm{B}$ and $\mathrm{D}$, children who rarely had a chance to put pieces of soil into the mouth

Table 5 Relationship of breast milk or formula feeding with blood dioxin concentration

\begin{tabular}{llll}
\hline $\begin{array}{l}\text { Group } \\
\text { Feeding mode }\end{array}$ & $\begin{array}{l}\text { Br } \\
\text { Breast milk only }\end{array}$ & $\begin{array}{l}\text { BrFo } \\
\text { Breast milk and formula }\end{array}$ & $\begin{array}{l}\text { Fo } \\
\text { Formula only }\end{array}$ \\
\hline Number of children & 17 & 44 & 5 \\
Age (years) & $6.6 \pm 0.83(6.0,3-15)$ & $7.0 \pm 0.46(6.5,3-15)$ & $7.0 \pm 1.2(8.0,3-10)$ \\
PCDDs + PCDFs (pg TEQ/g-lipid) & $12.0 \pm 2.0(9.8,3.5-33)$ & $5.5 \pm 0.63 *(4.4,0.85-21)$ & $4.1 \pm 0.89^{*}(4.0,1.3-6.6)$ \\
CoPCBs (pg TEQ/g-lipid) & $5.1 \pm 1.0(4.3,0.10-16)$ & $1.9 \pm 0.24^{* *}(1.3,0.053-6.3)$ & $0.64 \pm 0.33^{*}(0.097,0.091-1.5)$ \\
PCDDs + PCDFs + CoPCBs & $17.0 \pm 2.9(15,4.2-46)$ & $7.4 \pm 0.82^{* *}(5.9,0.94-26)$ & $4.7 \pm 1.1^{*}(4.8,1.4-8.1)$ \\
$\quad(p g$ TEQ/g-lipid) & & & \\
\hline
\end{tabular}

Values expressed as mean \pm SEM (median, range)

Asterisks indicate significant difference from group $\mathrm{Br}$ at $p<0.05(*)$ or $0.01(* *)$ by Steel-Dwass test

in nature (Fig. 3a-c). When the blood dioxin concentrations of group BrFo were included in the analysis, the correlation coefficients between blood dioxin concentrations and duration of breast feeding for PCDDs + PCDFs $\left(R^{2}=0.39, p<0.01\right)$, CoPCBs $\left(R^{2}=0.32, p<0.01\right)$, and PCDDs + PCDFs + CoPCBs $\left(R^{2}=0.40, p<0.01\right)$ became smaller (Fig. 3a-c). This is consistent with the data summarized in Table 5 and suggests that dioxins present in breast milk affect blood dioxin concentrations.

Next, we studied how fast blood dioxins are eliminated after cessation of breast feeding. The same blood dioxin concentration data used in Fig. 3 were plotted as a function 


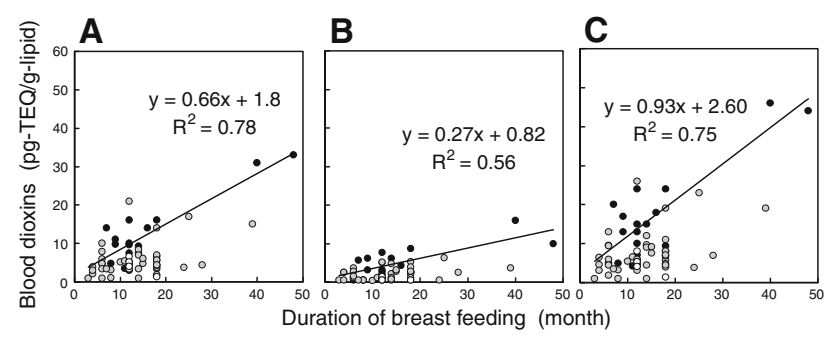

Fig. 3 Relationship of nursing period and blood dioxin concentrations: PCDDs + PCDFs (a), CoPCBs (b), and PCDDs + PCDFs + CoPCBs (c) on a TEQ basis. Breast (closed circle), mixed (breast and formula, gray circle), and formula (open circle) feedings are shown. The line and equation indicate an approximate estimate based on breast feeding
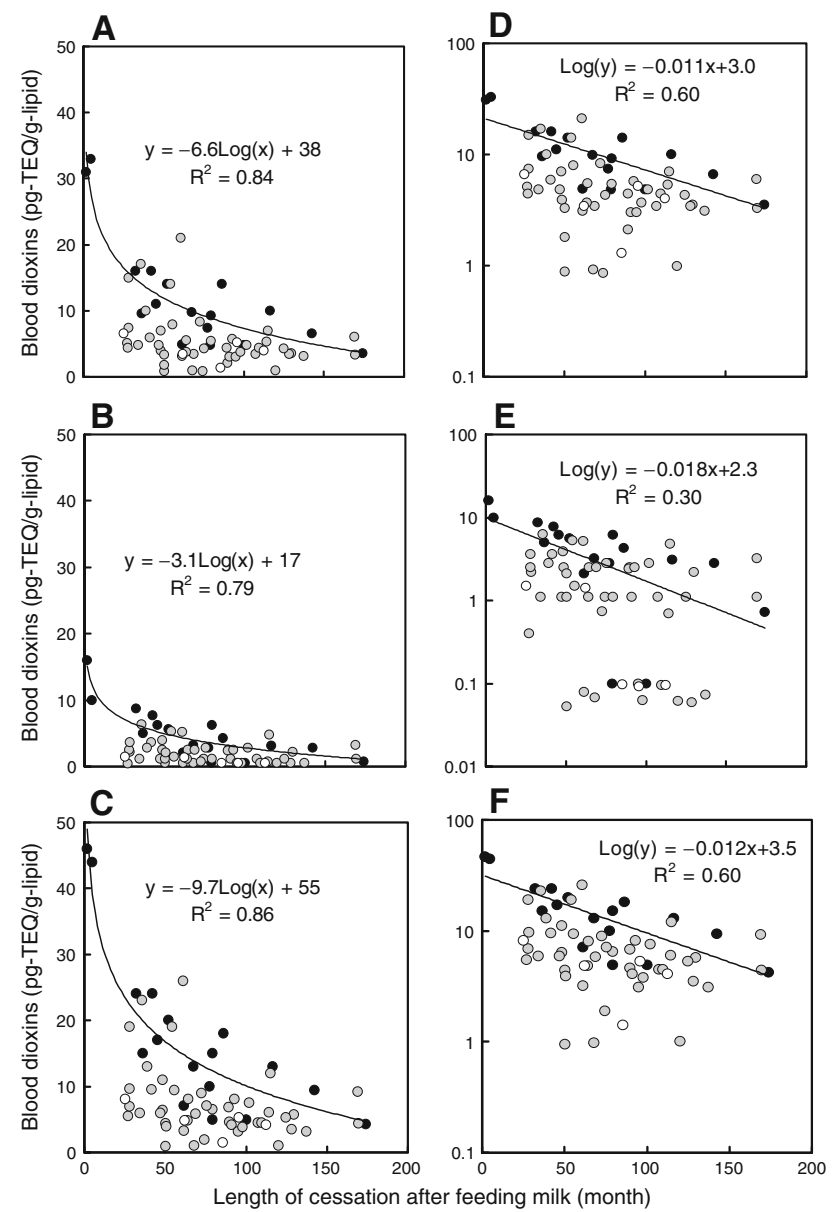

Fig. 4 Relationship of time after weaning to blood dioxin concentrations: PCDDs + PCDFs (a, d), CoPCBs (b, e), and PCDDs + PCDFs + CoPCBs (c, f) on a TEQ basis. Breast (closed circle), mixed (breast and formula, gray circle), and formula (open circle) feedings are shown. The line and equation indicate an approximate estimate based on breast feeding. Data are expressed on regular $(\mathbf{a}-\mathbf{c})$ and $\log (\mathbf{d}-\mathbf{f})$ scales

of length of time after cessation of breast feeding. When we drew the best-fit curve to estimate the relationship of blood dioxin concentrations with cessation of breast feeding, the dioxin concentrations, expressed as PCDDs + PCDFs, CoPCBs or PCDDs + PCDFs + CoPCBs, had statistically significant correlations $\left(R^{2}=0.84, p<0.01\right.$; $R^{2}=0.79, p<0.01 ; R^{2}=0.86, p<0.01$, respectively) as shown in Fig. $4 \mathrm{a}-\mathrm{c}$. The relationship between the two parameters appeared to be zero-order kinetics, and the blood dioxin concentrations were log-transformed to calculate apparent elimination half-lives for PCDDs + PCDFs, CoPCBs, and PCDDs + PCDFs + CoPCBs (Fig. 4d-f). Their apparent estimated elimination half-lives and $95 \%$ confidence interval (in parentheses) were calculated to be 5.4 (3.7-9.9), 3.3 (1.8-20.3), and 4.8 (3.3-8.8) years, respectively, although the cross-sectional data were utilized assuming that blood dioxin concentrations during breast feeding were similar among the given subjects.

\section{Discussion}

The principal objective of this survey is to evaluate the possible exposure of people who lived in a dioxin-contaminated area in the middle of Tokyo, and we could also study the possible relationship of feeding type (breast milk, formula or both) with blood dioxin concentrations by analyzing samples from children aged 3 to 15 years. The present results clearly show that blood concentrations of dioxins and related compounds in the current study population were similar to those obtained in Japan and Germany. Blood concentrations of dioxins including PCDDs, PCDFs, and CoPCBs of people living in different areas in Japan, monitored annually by the Ministry of the Environment, ranged from 0.64 to $96 \mathrm{pg} \mathrm{TEQ} / \mathrm{g}$-lipid (Table 2). In a German survey, blood dioxin concentrations of people aged between 29 and 42 years living in an industrialized area ranged from 4.34 to $97.3 \mathrm{pg} / \mathrm{g}$-lipid [15]. Thus, our present result is very similar to these values, suggesting that there is no significant direct contribution of exposure to dioxins and related compounds from the contaminated soil to people living in this area. Because the most plausible source of exposure to dioxins and related compounds has been established to be food commodities for people not exceedingly exposed to these chemicals occupationally or by accident [16], this is also naturally the case for the current target population in this study.

To further confirm this notion, we analyzed the results of the congener and isomer analyses of dioxins and related compounds, and found that soil and blood had a relatively large amount of 2,3,4,7,8-PeCDF on a TEQ basis, but that the congener patterns of the soil and blood samples clearly differed from each other; that is, blood samples had $42.5 \%$ PCDDs, 26.5\% PCDFs, and $31.1 \%$ CoPCBs contributions to total TEQ, and had five isomers [1,2,3,7,8-PeCDD, 2,3,4,7,8,-PeDEF， 3,3',4,4',5-PeCB (\#126), 1,2,3,6,7,8- 
HxCDD, and $3,3,4,4^{\prime}, 5,5^{\prime}$-HxCB (\#169)] on a TEQ basis, the patterns of which were similar to those shown in many other studies $[9,13]$. On the other hand, soil samples of the study area included a predominant amount of PCDFs rather than PCDDs and CoPCBs, and showed a unique congener pattern. Moreover, the contributions of PCDFs, PCDDs, and CoPCBs to total TEQ in this soil survey were $98.4 \%$, $1.35 \%$, and $0.29 \%$, respectively, which is completely different from the regular analysis of congeners in soil contaminated by incineration. Therefore, the congener pattern found in the present survey suggests that soil contamination was derived from PCDFs generated in anode electrolysis sludge of sodium chloride used in a black lead electrode and discharged from a chemical factory that had been in operation in this area 40 years ago. This speculation is consistent with previous findings [17, 18], which showed that anode electrolysis sludge of sodium chloride has an extremely high concentration of PCDFs. Thus, the present results strongly suggest that dioxins present in the contaminated soil were less likely to be taken up by the people who lived in the vicinity of the dioxin-contaminated area.

In this study, we could analyze the blood samples of children aged 3-12 years, because children and their parents were very cooperative in the survey carried out by the city health authority. Because of the scarcity of data on blood dioxin concentrations of Japanese children younger than 12 years, it was not possible to directly compare the data obtained in this study with those of populations having similar lifestyles and ethnicity. However, children aged 13-14 years, who might have been exposed to vapor or aerosol containing mainly PCBs due to the explosion of a stabilizer for a fluorescent light unit in a classroom, were examined for blood dioxin concentrations [14]. Results of their blood CoPCB concentrations showed that exposure of the students was considered negligible, and that their blood dioxin concentrations, ranging from 3.5 to $11 \mathrm{pg} \mathrm{TEQ} / \mathrm{g}-$ lipid with mean of $7.0 \mathrm{pg} \mathrm{TEQ} / \mathrm{g}$-lipid, were very similar to those of the children who participated in the current survey (Tables 1,2). Among the very limited studies on dioxin concentrations in infants, a German survey [19] showed that concentrations of PCDDs + PCDFs in the blood of 80 11-month-old infants, who were breast-fed for more than 4 months, ranged from 2 to $107 \mathrm{pg}$ TEQ/g-lipid with mean of $25.3 \mathrm{pg} \mathrm{TEQ} / \mathrm{g}$-lipid. In a Dutch survey [20], 3.5-year-old children were examined for blood PCB (one CoPCB, PCB118, and three other non-CoPCBs: PCBs 138, 153 , and 180) concentrations. Although only a single dioxin congener was determined in this Dutch survey, the breast-fed group $(N=91)$ and formula-fed group $(N=82)$ had PCB concentrations of 0.75 and $0.21 \mu \mathrm{g} / \mathrm{L}$, respectively, suggesting that breast feeding contributed the higher concentrations of PCBs, including a coplanar PCB. Our present investigation showed that breast-fed infants and formula-fed infants had blood dioxin concentrations, including a total of 29 congeners of PCDDs, PCDFs, and CoPCBs, of 17.0 and $4.7 \mathrm{pg}$ TEQ/g-lipid, respectively, showing that the blood dioxin concentration of the former was 3.6 times higher than that of the latter (Table 5). To estimate the body burden of dioxins in infants, Lorber and Phillips [21] used one-compartment pharmacokinetic analysis to predict a time-dependent trend of body burden of dioxins in infants assuming a starting mother's milk concentration as $25 \mathrm{pg}$ TEQ/g-lipid, and that the intake of dioxins from milk ranged from $242 \mathrm{pg} \mathrm{TEQ} / \mathrm{kg} /$ day just after birth to $18 \mathrm{pg}$ TEQ $/ \mathrm{kg} /$ day 1 year later. Their model predicts that the body burden of formula-fed infants will remain below $10 \mathrm{pg}$ TEQ/g-lipid during the first year, and that the body burden of dioxins of breast-fed infants will peak at $44 \mathrm{pg}$ TEQ/g-lipid at 9 weeks old. Their model also predicts that the dioxin body burden of breast-fed infants would be 6 times higher than that of formula-fed infants in the first year of life if breast feeding lasts longer than 6 months, and that this accumulated level would still be twice as high after 10 years. Our current study showed that infants nursed by breast milk only (group $\mathrm{Br}$ ) and those nursed by formula only (group Fo) had blood PCDDs + PCDFs + CoPCBs concentration ranges of 4.2$46 \mathrm{pg}$ TEQ/g-lipid and 1.4-8.1 pg TEQ/g-lipid (Table 5), respectively, with an apparent half-life of blood PCDDs + PCDFs + CoPCBs of 4.8 year (Fig. 4). Although there are limitations to the current analysis due to its cross-sectional nature, it seems that the results of our current study are consistent with the estimation using the actual survey results and the simulation using these preceding studies.

Infants tend to accumulate dioxins significantly by breast feeding in the first 1-2 years of life. According to a German study [15], individual exposures of infants due to breast feeding within the first 18 months were calculated to be from 4.4 to 318 ng TEQ (median 106 ng TEQ, arithmetic mean $118 \mathrm{ng}$ TEQ), and the actual mean daily exposure of a breast-fed infant can be estimated to be $131 \mathrm{pg} T E Q / \mathrm{kg}$ bw. In the Inuit population, breast milk that contains a median concentration of $48 \mathrm{pg}$ TEQ/g-lipid was estimated to correspond to a daily dose of $226 \mathrm{pg} \mathrm{TEQ} / \mathrm{kg}$ in infants [22]. Thus, the estimated intake level of dioxins would amount to 30-50 times the current TDI level of $4 \mathrm{pg}$ TEQ $/ \mathrm{kg}$, which has been adopted by the WHO and many other governments, including that of Japan. However, dioxins accumulated through 6 months of breast feeding were reported to be dissipated to the levels that formula-fed infants could have at 7 years of age. According to the pharmacokinetic prediction model for dioxins, the actual elimination pattern differs by age [21, 23], and accumulated dioxin levels decreased faster in the first 2 years of life. Because of the 
lack of samples from children younger than 3 years old, it was not possible to calculate the elimination half-life for the first 2 years in the present survey. In addition, because data were obtained from a cross-sectional survey and reflect the amount of dioxins at the age of being breast-fed, it should be noted that the elimination half-life could ideally be determined by performing a prospective cohort study of identical individuals. Nevertheless, the apparent elimination half-life estimated from the current survey for dioxins was calculated to be 57.8 months (or 4.8 years), derived from data for children aged 3-15 years using a regression equation (Fig. 4f). This elimination half-life is shorter than that of adults, i.e., 7-11 years, and it is considered that younger children have a shorter elimination half-life than adults [23].

In conclusion, this health survey shows that people living around the dioxin-contaminated area did not take in and accumulate an excess amount of dioxins from the soil of the playground and residential areas, and provides for the first time the blood dioxin concentrations of children aged 3-15 years. In this age group, blood dioxin levels seem to be strongly affected by breast feeding duration.

Acknowledgments The authors thank the people who participated in this survey and the officials in Kita City for their sincere cooperation in making this study possible.

\section{References}

1. Schecter A, Gasiewicz TA, editors. Dioxin and Health. 2nd ed. Hoboken: Wiley; 2003. p. 952.

2. World Health Organization. Consultation on assessment of the health risk of dioxins; re-evaluation of the tolerable daily intake (TDI): executive summary. Food Addit Contam. 2000;17:22340.

3. The Ministry of Health Labour and Welfare. Survey results on health effects of dioxins in workers who were engaged in incineration-related labors at Osaka Toyono-gun Cleanup Center. 2004. http://www.mhlw.go.jp/topics/2004/10/tp1020-2.html (in Japanese).

4. Uehara R, Peng GA, Nakamura Y, Matsuura N, Kondo N, Tada H. Human milk survey for dioxins in the general population in Japan. Chemosphere. 2006;62:1135-41.

5. Matsuura N, Uchiyama T, Tada H, Nakamura Y, Kondo N, Morita M, et al. Effects of dioxins and polychlorinated biphenyls (PCBs) on thyroid function in infants born in Japan-the second report from research on environmental health. Chemosphere. 2001;45:1167-71.

6. Furst P. Dioxins, polychlorinated biphenyls and other organohalogen compounds in human milk. Levels, correlations, trends and exposure through breastfeeding. Mol Nutr Food Res. 2006;50:922-33.

7. Konishi Y, Kuwabara K, Hori S. Continuous surveillance of organochlorine compounds in human breast milk from 1972 to
1998 in Osaka, Japan. Arch Environ Contam Toxicol. 2001;40:571-8.

8. Patandin S, Dagnelie PC, Mulder PGH, de Coul EO, van der Veen JE, Weisglas-Kuperus N, et al. Dietary exposure to polychlorinated biphenyls and dioxins from infancy until adulthood: a comparison between breast-feeding, toddler, and longterm exposure. Environ Health Perspect. 1999;107:45-51.

9. The Ministry of the Environment. Intensive survey on exposure levels of dioxins in humans in FY 2000-2001. 2002. http://www. env.go.jp/chemi/report/h20-04/chpt1.pdf (in Japanese).

10. Van den Berg M, Birnbaum LS, Denison M, De Vito M, Farland W, Feeley M, et al. The 2005 World Health Organization reevaluation of human and Mammalian toxic equivalency factors for dioxins and dioxin-like compounds. Toxicol Sci. 2006;93:223-41.

11. Kita City Office, Health survey on dioxins in Toshima area of Kita City. 2006. http://www.city.kita.tokyo.jp/docs/digital/ 165/016556.htm (in Japanese).

12. The Ministry of the Environment. Survey on dioxin accumulation in humans. 2006. http://www.env.go.jp/chemi/report/h20-04/chpt1. pdf (in Japanese).

13. Education Commission of the Hachioji City Office. The follow-up report on the blood dioxin levels after the report (Oct 2002) on a measure to protect health from PCB exposure. 2008. http://www.city.hachioji.tokyo.jp/dbps_data/_material_/localhost/ soshiki/shisetsuseibika/gakyo/pcbsaisyuuH19.pdf (in Japanese).

14. Masuzaki Y, Matsumura T, Hattori T, Kimura S, Noda H, Hashimoto $\mathrm{S}$, et al. Sensitive determination method of dioxins and related compounds in human blood. Organohalogen Compd. 1999;40:227-30.

15. Wittsiepe J, Furst P, Schrey P, Lemm F, Kraft M, Eberwein G, et al. PCDD/F and dioxin-like PCB in human blood and milk from German mothers. Chemosphere. 2007;67:S286-94.

16. Birmbaum LS, Farland WH. Health risk characterization of dioxins and related compounds. In: Shecter A, Gasiewicz TA, editors. Dioxins and health. Hoboken: Wiley; 2003. p. 159-190.

17. Strandell ML, De Wit C, Jarnberg U, Jansson B, Kjeller L, Kulp S, Ljung K, Soderstrom G, Rappe C. The Swedish survey: summary of results from PCDD/F and coplanar PCB analyses in source-related samples. Chemosphere 1994;20:363-366.

18. Yamamoto T, Higashino K, Sasaki Y. Dioxin formation in brine electrolysis processing using graphite electrode. In: 8th international symposium on halogenated persistent organic pollutants, Birmingham; 2008.

19. Abraham K, Papke O, Gross A, Kordonouri O, Wiegand S, Wahn $\mathrm{U}$, et al. Time course of $\mathrm{PCDD} / \mathrm{PCDF} / \mathrm{PCB}$ concentrations in breast-feeding mothers and their infants. Chemosphere. 1998;37:1731-41.

20. Patandin S, Weisglas-Kuperus N, de Ridder MA, KoopmanEsseboom C, van Staveren WA, van der Paauw CG, et al. Plasma polychlorinated biphenyl levels in Dutch preschool children either breast-fed or formula-fed during infancy. Am J Public Health. 1997;87:1711-4.

21. Lorber M, Phillips L. Infant exposure to dioxin-like compounds in breast milk. Environ Health Perspect. 2002;110:A325-32.

22. Ayotte P, Carrier G, Dewailly E. Health risk assessment for Inuit newborns exposed to dioxin-like compounds through breast feeding. Chemosphere. 1996;32:531-42.

23. Kerger BD, Leung HW, Scott PK, Paustenbach DJ. An adaptable internal dose model for risk assessment of dietary and soil dioxin exposures in young children. Toxicol Sci. 2007;100:224-37. 